\title{
REVIEW
}

\section{Male breast carcinoma: increased awareness needed}

\author{
Jonathan White', Olive Kearins², David Dodwell ${ }^{3}$, Kieran Horgan' ${ }^{1}$ Andrew M Hanby ${ }^{4}$ and Valerie Speirs ${ }^{4 *}$
}

\section{Abstract}

Male breast carcinoma is a rare condition. Few male breast cancer-specific epidemiological or clinical trial data are available - our understanding of male breast cancer thus comes from studies of female breast cancer, painting an inaccurate picture when it comes to determining contributing factors. Clinicians report an increase in diagnoses of male breast cancer but this has not been formally reported. We therefore undertook a review of data obtained from four western nations: England, Scotland, Canada and Australia. When adjusted for age, this review clearly showed an increase in the incidence of male breast cancer over a 15-year period. Reasons for the increased incidence are discussed in the context of suggested risk factors such as BRCA2 and lifestyle changes over the past few decades. The clinical management of male breast carcinoma is considered, in particular the potential role of aromatase inhibitors and fulvestrant and targeting pathways involving prolactin and androgen receptor.
\end{abstract}

\section{Introduction}

Breast cancer is predominantly a female disease with 49,492 cases (invasive and non-invasive) diagnosed in the UK in 2006 [1]. According to data from the International Agency for Research on Cancer, this is broadly in line with figures from other western nations [2]. Tremendous strides in our understanding of breast cancer have been made over the past two decades and, when detected early, breast cancer is one of the most curable and treatable of all cancers. Male breast cancer is much less frequent with 334 cases diagnosed in the UK in 2006 [1], accounting for just under $1 \%$ of all breast cancers.

${ }^{*}$ Correspondence: v.speirs@leeds.ac.uk

${ }^{4}$ Leeds Institute of Molecular Medicine, University of Leeds, Leeds LS9 7TF, UK Full list of author information is available at the end of the article

\section{Risk factors for male breast cancer}

Owing to the rarity of male breast cancer, establishing precise risk factors for the disease has proved challenging. Male and female breast cancers share many common risk factors; for example, advancing age and previous family history. In terms of male breast cancer, data from the Breast Cancer Linkage Consortium showed that men harbouring $B R C A 2$ mutations have a relative risk of 80 for developing breast cancer [3] - making BRCA2 the strongest known gene associated with male breast cancer $[4,5]$. Androgen receptor mutations have also been reported [6]. Some suggested risk factors associated with male breast cancer are summarised in Table 1 [4-8].

\section{Increasing incidence of male breast cancer}

Although still a rare disease, anecdotal evidence from clinical and pathology colleagues coupled with reports from recent literature suggests that male breast cancer is becoming more common [9-12]. As a means of corroborating this, we analysed data from four western nations: England, Scotland, Canada and Australia. Data for England were provided by the West Midlands Cancer Intelligence Unit [13]. Data for Scotland were obtained from the Information Services Division (Scotland) website [14]. Canadian data were obtained from the Public Health Agency of Canada [15], and data for Australia from the Australian Institute of Health and Welfare [16]. As the population of Scotland is considerably smaller than the other three nations, Scottish and English data were combined. Data were collected over a 15-year period (1991 to 2005) and were presented as absolute numbers and as World Health Organisation World Age Standardised Rates. Data for England were also available over a 20-year period (1986 to 2006).

As shown in Figure 1, our observations clearly show that the number of cases of invasive male breast carcinoma diagnosed over a 15 -year period has consistently increased in all countries. As well as increases in absolute numbers, age-adjusted incidence increased from 0.4 to 0.6 (England/Scotland), from 0.5 to 0.8 (Canada) and from 0.6 to 0.7 (Australia) per 100,000 population. Similar trends were observed when absolute numbers for 
Table 1. Suggested risk factors for male breast cancer

\begin{tabular}{ll}
\hline Risk factor & Explanation \\
\hline BRCA2 & BRCA2 mutations are associated with most inherited MBC \\
Klinefelter syndrome & Hereditary condition characterised by the 47XXY karyotype, which is consistently associated with MBC \\
Androgen receptor mutation & Germline mutations in AR predispose to MBC \\
CYP17 & Encodes cytochrome P450c17a, an enzyme involved in oestrogen and androgen biosynthesis \\
Cowden syndrome & Autosomal-dominant cancer susceptibility syndrome caused by germline mutation in the PTEN gene \\
CHEK2 & CHEK2*1100delC variants may increase risk of MBC by 10-fold \\
Endogenous oestrogen levels & Increased oestrogen levels as a result of obesity, male-female transsexuals and liver cirrhosis are all associated with MBC \\
Testicular disorders & Cryptorchidism, mumps orchitis, orchiectomy, congenital inguinal hernia and testicular injury are associated with MBC \\
Physical inactivity & Lack of exercise is associated with increased risk of MBC \\
\hline
\end{tabular}

Data obtained from [3-7]. These references include comprehensive discussion on other considered risk factors for male breast cancer (MBC). CHEK, cell-cycle checkpoint kinase.

England were considered over a 20-year period; a rise in incidence of one-third was observed from 185 cases in 1986 to 277 cases in 2006, which corresponded to 0.5 per 100,000 population in 1986 (95\% confidence interval, 0.4 to 0.6$)$ and to 0.7 per 100,000 population in 2006 (95\% confidence interval, 0.6 to 0.7 ). A limitation in our data was incomplete information on the stage of disease at presentation, and while increases observed in absolute numbers do not account for changing denominators over time, congruent changes in the age-adjusted incidence give confidence that these changes are real. Furthermore, our data parallel Surveillance, Epidemiology and End Results data published in 2004 showing that male breast carcinoma rates rose by $25 \%$ over a 26 -year period [9] and extend our earlier observation that was limited to a subset of UK cancer registries [12].

In the absence of formal epidemiological studies, reasons for the apparent rise in male breast cancer incidence can only be speculated. It is well recognised that lifestyle changes over the latter decades of the 20th century have led to increased obesity in western nations, which is rapidly becoming a global problem. This may be a contributing factor as obesity is linked to cancer predisposition, and breast cancer is no exception $[17,18]$. Increased alcohol intake is associated with increased relative risk of breast cancer [19], which may also play a role. Much more controversially, increased exposure to so-called environmental oestrogens via diet and household products have been mooted as potential risk factors for breast cancer development [20], but there are no substantive data to support this.

\section{Clinical management of male breast cancer General strategies}

The general approach for managing early male breast cancer is the same as that recommended for women. The therapeutic modalities employed include surgery, radiotherapy and systemic therapies. As many excellent expert overviews on the subject exist $[9,11,21]$, here we present only a brief summary. Surgical removal of the primary tumour by mastectomy or, rarely, by wide local excision is often accompanied by axillary node dissection, or, more recently, sentinel lymph node biopsy [22]. Adjuvant radiotherapy to the chest wall and draining lymphatic basin is often advised, especially in high-risk nodepositive groups, with the aim of reducing loco-regional recurrence, although there is a general lack of consensus on the optimal regimen [11]. Systemic therapies include chemotherapy, oral endocrine agents and, more recently, trastuzumab. Information on the potential benefit of adjuvant chemotherapy in men is also scarce, although the few published data support its use as the proportion of response is similar in males to that in females $[23,24]$.

\section{Endocrine therapies}

The importance of hormone manipulation in the management of male breast cancer was recognised as early as the 1940s when orchidectomy was first described as a treatment for skeletal metastases [25]. Patients persuaded to undergo orchidectomy were reported to experience rapid and dramatic relief of pain due to bony metastases. Proven regression of pulmonary metastases was demonstrated radiologically. Orchidectomy was also shown to elicit regression of the primary tumour in cases where it had not been removed surgically [26]. Other surgical procedures to alter the hormonal environment such as hypophysectomy and adrenalectomy have also been used. These were seen to be effective to some extent in the prevention of progression of metastatic disease but were not commonly used in the adjuvant setting. A metaanalysis of published case series of male patients with metastatic disease reported tumour regression rates of $55 \%$ for orchidectomy ( $n=355), 80 \%$ for adrenalectomy $(n=65)$ and $56 \%$ for hypophysectomy $(n=27)$, with an overall response rate of $59 \%$ in 447 patients [27]. These results should be interpreted with caution given that 


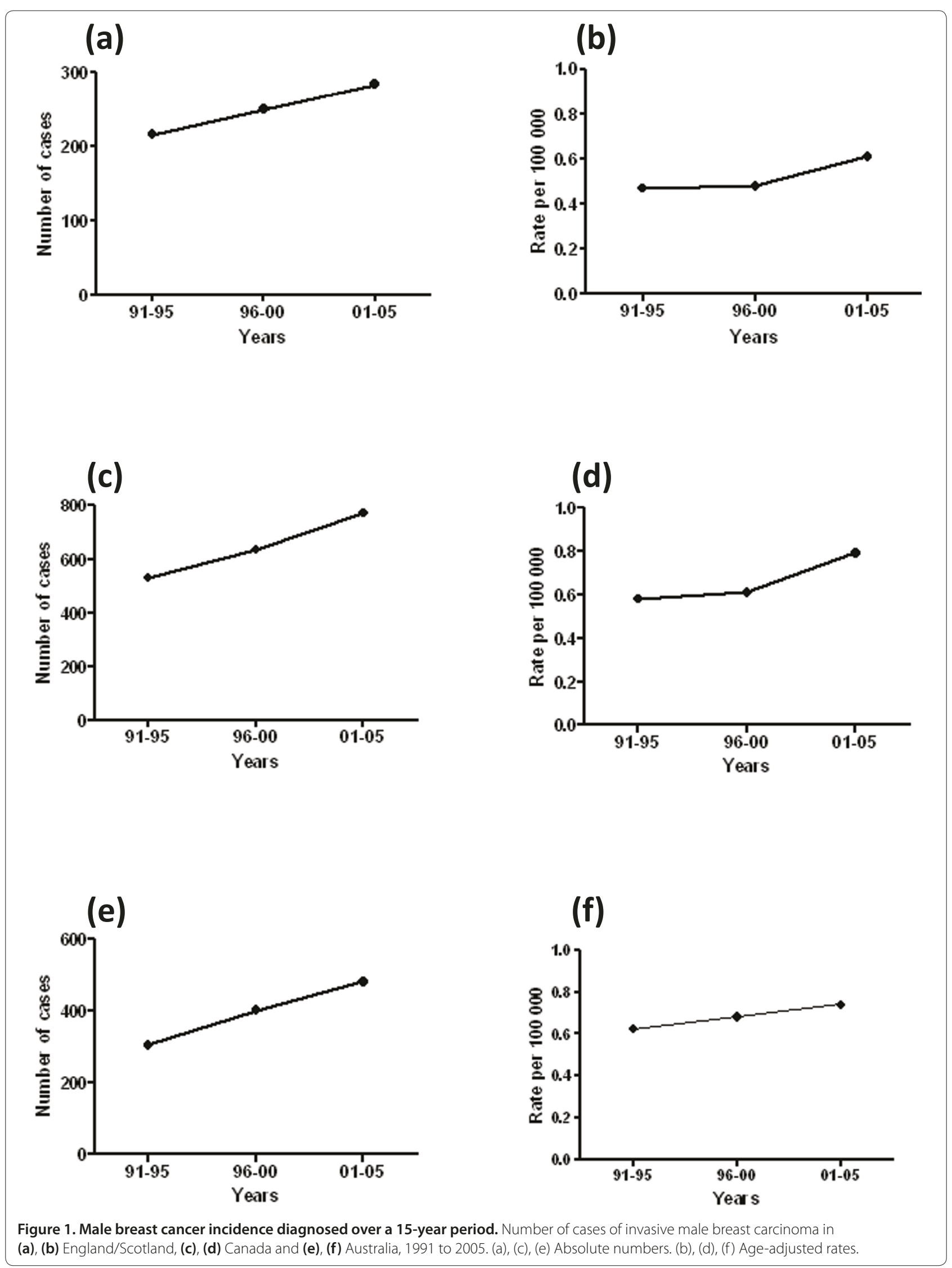


what constituted a successful response, and how this was measured, was not clearly defined in the meta-analysis. Nowadays, such invasive procedures are seldom, if ever, carried out, having been superseded by more advanced medical treatments.

There is conclusive evidence regarding the importance of oestrogen receptor measurement in female breast cancer, as the absence of receptors accurately predicts lack of sensitivity to endocrine therapy. As hormone receptor positivity for both oestrogen receptor and progesterone receptor is proportionally higher in male breast cancer than female breast cancer $[28,29]$, hormone therapies should be at least as effective in male breast cancer patients - thus most male breast cancer patients receive endocrine therapy.

Tamoxifen became established as part of the routine management of breast cancer in the 1970s [30]. Tamoxifen's efficacy in male breast cancer was first shown in a study of 24 patients, where tamoxifen treatment produced disease regression of $37.5 \%$, and was effective in treating metastases in soft-tissues, bone and lung [31]. Another study conducted on 41 patients also concluded that hormone therapy was successful in treating male breast cancer [32]. Further study has demonstrated that men treated with tamoxifen have a 51\% lower risk of recurrence, comparable with that seen in women $[28,33]$. Although this evidence is from relatively small retrospective studies or extrapolated from results in trials treating females with breast cancer, due to its efficacy and low cost, tamoxifen has gained widespread acceptance as the standard endocrine therapy in the treatment of hormone-sensitive male breast carcinoma [29,33,34]. Nevertheless, treatment with tamoxifen is associated with a multitude of side effects in men. Common problems include hair loss, skin rash, impotence, decreased libido, weight gain, hot flushes, mood changes, depression and insomnia. The incidence of these side effects may be as high as $62 \%$ and perhaps explains why compliance with tamoxifen is often poor [35].

The discovery that oestrogens are produced locally in breast tissues, by aromatisation of other sex steroid hormones [36], led to concerted efforts to exploit this pathway as a potential therapeutic target. Unlike tamoxifen, which is a selective oestrogen receptor modulator, aromatase inhibitors (AIs) prevent the conversion of androstenedione to $17 \beta$-estradiol. Data from large randomised clinical trials in females with breast cancer, in which the efficacy of AIs was compared with tamoxifen as an initial adjuvant endocrine therapy, or sequential (adjuvant tamoxifen or AI in either order) or extended (AI after 5 years of adjuvant tamoxifen) therapy, demonstrated a reduced risk of breast cancer recurrence compared with 5 years of tamoxifen treatment alone. AIs are now considered the therapy of choice for postmenopausal women with oestrogen receptor-positive breast cancer [37].

The use of AIs in male breast cancer was proposed due to their success in females and the identification of intratumoural aromatase in male breast cancer [38,39]. Despite hopes that aromatase inhibition would be useful in the management of metastatic disease in men, initial case series have disappointingly shown negative or equivocal results. In a series of five patients, none showed an objective response to treatment with anastrozole [40]. Interestingly, however, there have been three reported individual cases of response to letrozole alone in men [41-43]. In a recent Canadian study, eight male breast cancer patients were treated with anastrozole (three in the adjuvant setting and five in the metastatic setting), with three of the cohort experiencing side effects including depression, decreased libido and lower-limb oedema [44]. In the same series, letrozole was prescribed to five patients in the metastatic setting after prior tamoxifen treatment, with two out of five experiencing oedema. Despite these side effects, none of the patients in this study discontinued treatment with either of these AIs.

In animal models, aromatase inhibition increases levels of follicle-stimulating hormone and testosterone but oestrogen levels are almost unchanged [45]. Moreover, a fall in oestrogen levels of $50 \%$ was seen in studies where anastrozole was given to healthy male volunteers, but this is not as dramatic as in females where AIs were shown to cause a $98 \%$ reduction. Administration of anastrozole in men, however, was also associated with a significant increase of $58 \%$ in the levels of circulating testosterone [46]. By contrast, administered at a similar dose to that used in women, letrozole treatment resulted in a 70 to $80 \%$ reduction in oestrogen levels in men [47]. Given that around $20 \%$ of circulating oestrogen is produced by the testis, this represents an almost total blockade of peripheral aromatisation.

In what is, to date, the most extensive description of the use of AIs for metastatic male breast cancer in the literature, Doyen and colleagues reported a complete tumour response in 13\% (two patients), partial response in $27 \%$ (four patients), stable disease in 13\% (two patients) and progressive disease in $47 \%$ (seven patients) [48]. Only six of the 15 patients in this study were assessed with regard to their serum oestrogen levels. In each of these cases, oestrogen levels fell below the minimum limit of detection after commencement of AI. The treatment response in this group varied, with three patients having partial response, one patient having stable disease and two patients showing progression [48]. Understanding why progression occurs in the almost complete absence of oestrogen requires further investigation.

The increase in testosterone seen after aromatase inhibition has been suggested to effectively overcome the 
oestrogenic aromatase blockade by flooding the enzyme pathway with substrate, leading to only modest reduction in serum oestrogen. Combination therapy with a gonadotrophin-releasing hormone agonist effectively reduces the excess substrate and maximises the effect of aromatase inhibition, and has been seen to cause regression in male patients with disease refractory to aromatase inhibition alone [49]. This observation requires further evaluation and may allow more frequent use of AIs in males, possibly in combination with a gonadotrophinreleasing hormone agonist. The SWOG-S0511 trial - a small, phase 2 trial of 56 patients with recurrent or metastatic disease, in which goserelin is administered subcutaneously on day 1 followed by oral anastrozole for 28 days for 12 cycles - has been designed to help answer these questions [50]. This trial has completed recruitment and the results are awaited.

Other available endocrine therapies include the pure anti-oestrogen fulvestrant, a selective oestrogen receptor downregulator, currently only licensed for use in advanced breast cancer in women. There are only three reports of its success in metastatic male breast cancer [51-53]. The most recent study evaluated five patients with metastatic disease and observed either partial response or disease stability in three out of five patients, concluding that fulvestrant should be considered as a treatment option in pretreated metastatic male breast cancer patients [53].

\section{Other potential therapeutic strategies}

Although not exclusive to male breast cancer, other putative novel therapeutic targets include prolactin receptor and androgen receptor. The presence of prolactin receptor in both benign and malignant male breast tissue varies according to the site of expression; benign lesions only express the receptors on the luminal surface of epithelial cells, while malignant lesions show cytoplasmic expression [54-56]. Moreover, male breast cancer was reported in the context of hyperprolactinaemia [57]. Owing to local production of prolactin in breast tissue, where it acts as a paracrine hormone [58], the potential of the targeting pathway as a putative therapeutic target is receiving increased attention [59]. A study of 251 male breast cancers indicated a potential role for androgen receptor as a therapeutic target following the association of androgen receptor positivity with better outcome [60], paralleling similar observations in a series of 953 female breast cancers [61] - suggesting that there is potential to explore anti-androgen therapies as a therapeutic approach.

\section{Public education}

The general public consider breast cancer very much a female disease, and a diagnosis of male breast cancer is often met with a sense of disbelief [62]. Pink ribbon campaigns have been hugely successful at promoting breast cancer awareness on an international level and, although direct evidence is lacking, these campaigns may have contributed to earlier detection, which makes the disease much more treatable. However, these campaigns remain very much female focused. The pink and blue ribbon developed by the John W Nick Foundation is aimed at promoting breast cancer awareness in men [63]. As male breast cancer incidence is undoubtedly rising, it would seem sensible to promote this in tandem with pink ribbons as a way of educating the public about the disease in men.

\section{Conclusion}

Although rates of male breast cancer are increasing, the cancer remains rare. Few direct epidemiological or clinical trial data are thus available and nearly all information used in understanding male breast cancer comes from studies of female breast cancer, which undoubtedly provides an inaccurate picture. More recently, genderrelated differences in gene profiles have been reported $[64,65]$. Although both studies emphasised caveats associated with their cohort sizes, the differences reported provide a stimulus to dissect out potential differences in the biology of male and female breast cancer. In addition, two very timely articles outlining the development of the Male Breast Cancer Consortium [66] and an International Male Breast Cancer Program [67] offer further hope for much-needed progress. Both studies will examine biomarker profiles in male breast cancer, with the latter offering the additional prospect of a male breast cancerspecific clinical trial. Whilst accrual is likely to be slow, international effort can only facilitate this. These collections will provide important resources for the study of male breast cancer, something we consider is much needed in order to advance our understanding of the biology and natural history of this rare but increasingly recognised carcinoma.

\section{Abbreviations}

$\mathrm{Al}$, aromatase inhibitor.

\section{Competing interests}

The authors declare that they have no competing interests.

\section{Acknowledgements}

Our male breast cancer programme is supported by Breast Cancer Campaign and Yorkshire Cancer Research.

\section{Author details}

'Department of Surgery, Leeds General Infirmary, Great George Street, Leeds LS1 3EX, UK. ${ }^{2}$ West Midlands Cancer Intelligence Unit, Public Health Building, University of Birmingham, Birmingham B15 2TT, UK. ${ }^{3}$ St James's Institute of Oncology, St James's University Hospital, Leeds LS9 7TF, UK. ${ }^{4}$ Leeds Institute of Molecular Medicine, University of Leeds, Leeds LS9 7TF, UK.

Published: 29 September 2011 


\section{References}

1. All Breast Cancer Report [http://www.cancerscreening.nhs.uk/breastscreen/ all-breast-cancer-report.pdf]

2. Parkin DM, Whelan SL, Ferlay J, Teppo L, Thomas DB (Eds): Cancer Incidence in Five Continents Vol. VIII. IARC Scientific Publication No. 155. Lyon: IACR Press; 2002.

3. Thompson D, Easton D; Breast Cancer Linkage Consortium: Variation in cancer risks, by mutation position, in BRCA2 mutation carriers. Am J Hum Genet 2001, 68:410-419.

4. Thorlacius S, Olafsdottir G, Tryggvadottir L, Neuhasen S, Jonasson JG, Tavtigian SV, Tulnius H, Ogmunsdottir HM, Eyfjord JE: A single BRCA2 mutation in male and female breast cancer families from Iceland with varied cancer phenotypes. Nat Genet 1996, 13:117-119.

5. Thorlacius S, Tryggvadottir L, Olafsdottir GH, Jonasson JG, Ogmunsdottir HM,

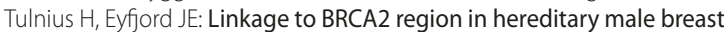
cancer. Lancet 1995, 346:544-545.

6. Weiss JR, Moysich KB, Swede H: Epidemiology of male breast cancer. Cancer Epidemiol Biomarkers Prev 2005, 14:20-26.

7. Brinton LA, Richesson DA, Gierach GL, Lacey JV Jr, Park Y, Hollenback AR, Schatzkin A: Prospective evaluation of risk factors for male breast cancer. J Natl Cancer Inst 2008, 100:1477-1481.

8. Alali L, Honarpisheh H, Shaaban AM, Speirs V: Conditions of the male breast: gynaecomastia and male breast cancer. Mol Med Rep 2010, 3:21-26.

9. Giordano SH, Cohen DS, Buzdar AU, Perkins G, Hortobagyi GN: Breast carcinoma in men: a population-based study. Cancer 2004, 101:51-57.

10. Hodgson NC, Button JH, Franceschi D, Moffat FL, Livingstone AS: Male breast cancer: is the incidence increasing? Ann Surg Oncol 2004, 11:751-755.

11. Contractor KB, Kaur K, Rodrigues GS, Kulkarni DM, Singhal H: Male breast cancer: is the scenario changing. World J Surg Oncol 2008, 6:58-69.

12. Speirs $V$, Shaaban AM: The rising incidence of male breast cancer. Breast Cancer Res Treat 2009, 115:429-430.

13. West Midlands Cancer Intelligence Unit [http://www.wmpho.org.uk]

14. Information Services Division (Scotland) [http://www.isdscotland.org/ isd/3348.html]

15. Public Health Agency of Canada [http://www.publichealth.gc.ca]

16. Australian Institute of Health and Welfare [http://www.aihw.gov.au/]

17. Calle EE, Kaaks R: Overweight, obesity and cancer: epidemiological evidence and proposed mechanisms. Nat Rev Cancer 2004, 4:579-591.

18. Lahmann PH, Hoffmann K, Allen N, van Gils CH, Khaw KT, Tehard B, Berrino F, Tjønneland A, Bigaard J, Olsen A, Overvad K, Clavel-Chapelon F, Nagel G, Boeing H, Trichopoulos D, Economou G, Bellos G, Palli D, Tumino R, Panico S, Sacerdote C, Krogh V, Peeters PH, Bueno-de-Mesquita HB, Lund E, Ardanaz E, Amiano P, Pera G, Quirós JR, Martínez C, et al.: Body size and breast cancer risk: findings from the European Prospective Investigation into Cancer and Nutrition (EPIC). Int J Cancer 2004, 111:762-771.

19. Khan N, Afaq F, Mukhtar H: Lifestyle as risk factor for cancer: evidence from human studies. Cancer Lett 2010, 293:133-143.

20. Darbre PD, Charles AK: Environmental oestrogens and breast cancer: evidence for combined involvement of dietary, household and cosmetic xenooestrogens. Anticancer Res 2010, 30:815-827.

21. Agrawal A, Ayantunde AA, Rampaul A, Robertson JFR: Male breast cancer: a review of clinical management. Breast Cancer Res Treat 2007, 103:11-21.

22. De Cicco C, Baio SM, Veronesi P, Trifirò G, Ciprian A, Vento A, Rososchansky J, Viale G, Paganelli G: Sentinel node biopsy in male breast cancer. Nucl Med Commun 2004, 25:139-143.

23. Bagley CS, Wesley MN, Young RC. Lippman ME: Adjuvant chemotherapy in males with cancer of the breast. Am J Clin Oncol 1987, 10:55-60.

24. Patel HZ 2nd, Buzdar AU, Hortobagyi GN: Role of adjuvant chemotherapy in male breast cancer. Cancer 1999, 64:1583-1585

25. Farrow JH, Adair FE: Effect of orchidectomy on skeletal metastases from cancer of the male breast. Science 1942, 95:654.

26. Treves N: The treatment of cancer, especially inoperable cancer, of the male breast by ablative surgery (orchiectomy, adrenalectomy, and hypophysectomy) and hormone therapy (oestrogens and corticosteroids); an analysis of 42 patients. Cancer 1959, 12:820-882

27. Jaiyesimi IA, Buzdar AU, Sahin AA, Ross MA: Carcinoma of the male breast. Ann Intern Med 1992, 117:771-777.

28. Giordano SH, Buzdar AU, Hortobagyi GN: Breast cancer in men. Ann Intern Med 2002, 137:678-687.

29. Murphy CE, Carder PJ, Lansdown MR, Speirs V: Steroid hormone receptor expression in male breast cancer. Eur J Surg Oncol 2006, 32:44-47.
30. Baum M, Brinkley DM, Dossett JA, McPherson K, Patterson JS, Rubens RD Smiddy FG, Stoll BA, Wilson A, Lea JC, Richards D, Ellis SH: Improved survival among patients treated with adjuvant tamoxifen after mastectomy for early breast cancer. Lancet 1983, 2:450.

31. Ribeiro GG: Tamoxifen in the treatment of male breast carcinoma. Clin Radiol 1983, 34:625-628.

32. Kantariian H, Yap HY, Hortobagyi G, Buzdar A, Blumenschein G: Hormonal therapy for metastatic male breast cancer. Arch Intern Med 1983 143:237-240

33. Giordano SH, Perkins GH, Broglio K, Garcia SG, Middleton LP, Buzdar AU, Hortobagyi GN: Adjuvant systemic therapy for male breast carcinoma. Cancer 2005, 104:2359-2364.

34. Vinod SK, Pendlebury SC: Carcinoma of the male breast: a review of adjuvant therapy. Australas Radiol 1999, 43:69-72.

35. Meguerditchian AN, Falardeau M, Martin G: Male breast carcinoma. Can J Surg 2002, 45:296-302.

36. Pasqualini JR, Chetrite G, Nguyen B-L, Maloche C, Delalonde L, Talbi M, Feinstein MC, Blacker C, Botella J, Paris J: Estrone sulfate-sulfatase and 17 $\beta$ hydroxysteroid dehydrogenase activities: a hypothesis for their role in the evolution of human breast cancer from hormone-dependence to hormone-independence. J Steroid Biochem 1995, 53:407-412.

37. Burstein HJ, Prestrud AA, Seidenfeld J, Anderson H, BuchholzTA, Davidson NE, Gelmon KE, Giordano SH, Hudis CA, Malin J, Mamounas EP, Rowden D, Solky AJ, Sowers MR, Stearns V, Winer EP, Somerfield MR, Griggs JJ: American Society of Clinical OncologyAmerican Society of Clinical Oncology clinical practice guideline: update on adjuvant endocrine therapy for women with hormone receptor-positive breast cancer. J Clin Oncol 2010, 28:3784-3796

38. Sasano H, Kimura M, Shizawa S, Kimura N, Nagura H: Aromatase and steroid receptors in gynecomastia and male breast carcinoma: an immunohistochemical study. J Clin Endocrinol Metab 1996, 81:3063-3067.

39. Dakin Haché K, Gray S, Barnes PJ, Dewar R, Younis T, Rayson D: Clinical and pathological correlations in male breast cancer: intratumoral aromatase expression via tissue microarray. Breast Cancer Res Treat 2007, 105:169-175.

40. Giordano SH, Valero V, Buzdar AU, Hortobagyi GN: Efficacy of anastrozole in male breast cancer. Am J Clin Oncol 2002, 25:235-237.

41. Italiano A, Largillier R, Marcy PY, Foa C, Ferrero JM, Hartmann MT, Namer M: Complete remission obtained with letrozole in a man with metastatic breast cancer. Rev Med Interne 225:323-324

42. Zabolotny BP, Zalai CV, Meterissian SH: Successful use of letrozole in male breast cancer: a case report and review of hormonal therapy for male breast cancer. J Surg Oncol 2005, 90:26-30.

43. Arriola E, Hui E, Dowsett M, Smith IE: Aromatase inhibitors and male breast cancer. Clin Transl Oncol 2007, 9:192-194.

44. Visram H, Kanji F, Dent SF: Endocrine therapy for male breast cancer: rates of toxicity and adherence. Curr Oncol 2010, 17:17-21.

45. Turner KJ, Morley M, Atanassova N, Swanston ID, Sharpe RM: Effect of chronic administration of an aromatase inhibitor to adult male rats on pituitary and testicular function and fertility. J Endocrino/ 2000, 164:225-238.

46. Mauras N, O'Brien $\mathrm{KO}$, Klein $\mathrm{KO}$, Hayes V: Oestrogen suppression in males: metabolic effects. J Clin Endocrinol Metab 2000 85:2370-2377.

47. Trunet PF, Mueller P, Bhatnagar AS, Dickes I, Monnet G, White G: Open dosefinding study of a new potent and selective nonsteroidal aromatase inhibitor, CGS 20 267, in healthy male subjects. J Clin Endocrinol Metab 1993, 77:319-323.

48. Doyen J, Italiano A, Largillier R, Ferrero JM, Fontana X, Thyss A: Aromatase inhibition in male breast cancer patients: biological and clinical implications. Ann Oncol 2010, 21:1243-1245.

49. Giordano $\mathrm{SH}$, Hortobagyi GN: Leuprolide acetate plus aromatase inhibition for male breast cancer. J Clin Oncol 2006, 24:e42-e43.

50. National Cancer Institute Clinical Trials (PDQ) [http://www.cancer.gov/ clinicaltrials/SWOG-S0511\#Outline CDR0000442919]

51. Agrawal A, Cheung KL, Robertson JF: Fulvestrant in advanced male breast cancer. Breast Cancer Res Treat 2007, 101:123.

52. de la Haba Rodriguez JR, Porras Quintela I, Pulido Cortijo G, Berciano Guerrero M, Aranda E: Fulvestrant in advanced male breast cancer. Ann Oncol 2009, 20:1896-1897.

53. Masci G, Gandini C, Zuradelli M, Pedrazzoli P, Torrisi R, Lutman FR, Santoro A: Fulvestrant for advanced male breast cancer patients: a case series. Ann Oncol 2011, 22:985-993.

54. Agarwal PK, Tandon S, Agrawal AK, Kumar S: Highly specific sites of prolactin 
binding in benign and malignant breast tissue. Indian J Exp Biol 1989, 27:1035-1038

55. Gill S, Peston D, Vonderhaar BK, Shousha S: Expression of prolactin receptors in normal, benign, and malignant breast tissue: an immunohistological study. J Clin Pathol 2001, 54:956-960.

56. Ferreira M, Mesquita M, Quaresma M, Andre S: Prolactin receptor expression in gynaecomastia and male breast carcinoma. Histopathology 2008, 53:56-61.

57. Forloni F, Giovilli M, Pecis C, Bortolani E, Preziosi A, Barzaghi ME, Corti D, BeckPeccoz P: Pituitary prolactin-secreting macroadenoma combined with bilateral breast cancer in a 45-year-old male. J Endocrinol Invest 2001, 24:454-459.

58. Wennbo $\mathrm{H}$, Tornell J: The role of prolactin and growth hormone in breast cancer. Oncogene 2000, 19:1072-1076.

59. Clevenger CV, Gadd SL, Zheng J: New mechanisms for PRLr action in breast cancer. Trends Endocrinol Metab 2009, 20:223-229

60. Speirs V, Shabban AM, Pollock S, Hanby AM, Ball GR; The Male Breast Cancer Consortium: Male versus female breast cancer: study of 523 matched cases reveals differences behind similarity [abstract]. J Pathol 2010, 222:s8.

61. Castellano I, Allia E, Accortanzo V, Vandone AM, Chiusa L, Arisio R, Durando A, Donadio M, Bussolati G, Coates AS, Viale G, Sapino A: Androgen receptor expression is a significant prognostic factor in oestrogen receptor positive breast cancers. Breast Cancer Res Treat 2010, 124:607-617.

62. Iredale R, Brain K, Williams B, France E, Gray J: The experiences of men with breast cancer in the United Kingdom. Eur J Cancer 2006, 42:334-341.
63. John W Nick Foundation [https://malebreastcancer.org/Home_Page.php]

64. Callari M, Cappelletti V, De Cecco L, Musella V, Miodini P, Veneroni S, Gariboldi M, Pierotti MA, Daidone MG: Gene expression analysis reveals a different transcriptomic landscape in female and male breast cancer. Breast Cancer Res Treat 2009. doi:10.1007/s10549-010-1015-8.

65. Johansson I, Nilsson C, Berglund P, Strand C, Jönsson G, Staaf J, Ringnér M, Nevanlinna H, Barkardottir RB, Borg A, Olsson H, Luts L, Fjällskog ML, Hedenfalk I: High-resolution genomic profiling of male breast cancer reveals differences hidden behind the similarities with female breast cancer. Breast Cancer Res Treat 2010. doi:10.1007/s10549-010-1262-8.

66. Speirs V, Pollock S, Shaaban AM, Hanby AM: Problems (and solutions) in the study of male breast cancer. Rare Tumors 2010, 2:78.

67. Korde LA, Zujewski JA, Kamin L, Giordano S, Domchek S, Anderson WF, Bartlett JM, Gelmon K, Nahleh Z, Bergh J, Cutuli B, Pruneri G, McCaskillStevens W, Gralow J, Hortobagyi G, Cardoso F: Multidisciplinary meeting on male breast cancer: summary and research recommendations. J Clin Oncol 2010, 28:2114-2122.

doi:10.1186/bcr2930

Cite this article as: White J, et al.: Male breast carcinoma: increased awareness needed. Breast Cancer Research 2011, 13:219. 